$\begin{gathered}\text { EPiC Series in Built Environment } \\ \text { Volume 2, 2021, Pages 367-376 } \\ \text { ASC 2021. 57th Annual Associated Schools } \\ \text { of Construction International Conference }\end{gathered}$
Built
Environment

\title{
Construction Management Department - Journeyman International: Case Study of an Academic - Philanthropic Partnership
}

\author{
Philip L. Barlow, Ph.D. \& Daniel Wiens \\ California Polytechnic State University \\ San Luis Obispo, California
}

\begin{abstract}
Over the years university educators and philanthropic organizations have strived to come together to achieve the goals and objectives of both. Construction management programs are often seen as a prime potential partner to assist with community construction projects which benefit non-profit organizations. At the same time, construction management educators have strived to provide their students with service-learning opportunities that are construction related, interdisciplinary, and project-based. This paper presents and describes the origins and functionality of a new model which integrates a university construction management senior project program with an international nonprofit organization to provide design, engineering, and pre-construction services to international community construction projects in third-world countries. This case study was developed through accounts provided by the authors (originators of the program) and a series of student evaluations and surveys from twenty-three construction management students who participated in the program over a four-year-time period. The results and analysis describe a highly successful program through a model which benefits both the non-profit and educational institution through interdisciplinary collaboration and service learning. This paper is beneficial to educators and non-profit organizations who are looking for new and effective ways of achieving similar goals and objectives for both institutions.
\end{abstract}

Key Words: Service-Learning, Collaboration, Interdisciplinary, Project-Based, Construction Education

\section{Introduction}

College universities have repeatedly struggled to find ways to incorporate academic pursuits with philanthropic projects that serve and positively impact both student learning and non-profit organizations. Bringing philanthropic projects together with academic pursuits is an admirable goal, but it is not without significant challenges. Even when academic-philanthropic partnerships do come 
together successfully, it is often for just a single project and involves only one or two individual students. Rarely are the activities developed repeatable and/or extended over a long period of time. The one-off nature of these pursuits greatly limits the impact of these partnerships on communities and the number of students able to benefit from their participation. The inability to leverage one's efforts is a disincentive to professors looking to maximize their time and educational impact through scalable endeavors. When these challenges are overcome, the impact on students and non-profit organizations is significant and long lasting. When collaboration with this level of success is achieved, the efforts should be documented, studied, and reported for the benefit of others interested in achieving similar goals.

This case study builds on the existing frameworks of service-learning, project-based learning, and interdisciplinary education practices. When these are interwoven in the construction education landscape, the student receives a rich and robust learning experience. This paper studied a long-term and ongoing collaboration between Journeyman International (JI) and the Construction Management Department at Cal Poly San Luis Obispo. This unique relationship stemmed from a former construction management student's desire to recreate his own senior project undergraduate experience for the benefit of future students. The aim of this paper is to document and more fully explain this collaboration, so other programs can benefit from understanding this model. This case study examined the relationship between JI and Cal Poly CM from its inception and gives a construction management student's perspective of the program through detailed student evaluations and surveys.

\section{Literature Review}

Community outreach through construction project-based service-learning projects supports the mission of most universities to serve, improve, and positively engage the surrounding communities of which they are a part (Holley et al., 2012). There is an extensive history of service-learning and community outreach programs developed by university design and construction programs over the years (Hardin et al., 2006). Serving in this way not only benefits the community but the students who are involved with a real community enhancing construction project. Often, when service-learning content is injected into a curriculum, it is done in collaboration with the local community and taught as a traditional course. For example, a construction service-learning course was developed at $\mathrm{Cal}$ Poly which identified smaller construction projects in the community that could be completed by students within a short academic quarter (Barlow, 2009). The documented and undocumented examples of successful construction management service-learning programs are many (Bernstein, 2006; Maldonado \& Moore, 2010; Hwang and McCrary, 2010; Olbina et al., 2018). What all of these programs have in common is a focus on providing construction services which support both the non-profit organization and the academic participants.

However, the development and perpetual implementation of service-learning project-based programs can be daunting for educators (Cline et al., 2014). The front-end work needed to ensure a successful project and a quality learning experience is difficult and is often done as an overload on top of the professor's normal teaching load. The difficulties increase as the goal then becomes recreating this high-value student-learning experience each academic cycle, with the hope to increase the programs impact on the number of students who can participate. Even with small community projects, concerns arise regarding logistics, transportation, and safety. As valuable as physically constructing these projects are at engaging construction management students in this way, they clearly have their limitations. One solution is engaging students in the design and pre-construction services of a project (Holley et al., 2012). Through this emphasis, Holley's program at Auburn University was able to 
utilize larger scale construction projects which added significant depth and breadth to the student's learning experience. Highlighting the design management aspects of the project also presented an opportunity to make them interdisciplinary resulting in an attractive pedagogical benefit.

University educators have strived to provide university students with an international experience. This has also proven to be a formidable task. Modern construction professionals are expected to function in cross-cultural environments with multinational teams to overcome geographic challenges and be familiar with construction means and methods of foreign countries (Soibelman, et al., 2011). A student's international experience is perceived to be so important that many universities have considered making it mandatory for all students. A recent strategic plan at Auburn University challenged faculty and administrators to provide all students with an international experience in five years (Farrow et al., 2011). Academics and students alike speak intuitively about the substantial benefits of a study abroad programs. Lu, Connell, and Wang (2009) quantified these benefits through surveys with participating students showing growth in their global perspective, personality development, and acquisition of new knowledge in construction management. Bringing together an international construction community also exposes students to different cultures, history, and business principles (Ruwanpura and Brown, 2006). Other purported features include students gleaning a global perspective and exhibiting gains in personal growth. Additional benefits also noted an improvement with interpersonal skills, language acquisition, cross-cultural skills, and cultural sensitivity. These kinds of experiences are highly impactful on students who often lack the opportunity to work on large scale construction projects in a foreign setting.

\section{Case Study Background}

This case study describes the successful collaboration of a philanthropic organization (Journeyman International) with an academic institution (Cal Poly, SLO) in an effort to offer students an opportunity to benefit and learn from a genuine international humanitarian project-based service learning experience. This new collaborative model exposes student participants to pedagogical elements of service-learning, experiential-learning, and interdisciplinary-collaboration through an undergraduate thesis/capstone senior project experience in a third-world setting. As identified previously, many academic-philanthropic partnerships have achieved various levels of success in each of these areas, but few have had the opportunity to combine all of these elements in a sustainable way. This paper presents a qualitative case study to disseminate the results of an ongoing program that the authors believe demonstrates an unusual type of collaborative program which can be either duplicated and/or utilized by other universities.

\section{Journeyman International (JI)}

Journeyman International's (JI) mission is: (1) inspire and train the next generation of humanitarians and (2) connect design volunteers with humanitarian non-government organizations (NGO's), empowering these organization with designs that are environmentally, socially, structurally and economically appropriate (JI, 2019). This mission statement is accomplished through JI by engaging architect, engineering, and construction (AEC) university students pursuing their thesis (or senior) project and combining them with real proposed projects in needy communities throughout the world.

Founded in 2009 the 501c3 non-profit organization, Journeyman International, has maintained a strong existence to date with an impressive resume of accomplishments. According to Journeyman International's 2017 annual report, these include:

- 80,000 hours of design, engineering, and construction services have been donated.

- $\$ 3.2$ million dollars of services have been provided to humanitarian partners. 
- 30 projects have been either constructed or are in construction.

- 250 project proposals have been presented predominately in $3^{\text {rd }}$ world countries

The utilization of student work through their academic senior thesis efforts, allows JI to significantly leverage the actual hard money raised. Through this model, JI's fundraising efforts resulted in fifteen times the amount of design and construction services that could be provided professionally. Last year, this financial model turned $\$ 100,000$ of hard dollar sponsorship into $\$ 1,500,000$ worth of architecture, engineering, and construction services for humanitarian projects which were not affordable or able to attract these services in the open market (JI, 2018). The projects JI selects are designed and constructed for charitable non-profit organizations in the neediest places in the world. The humanitarian aspect instills a sense of doing-good which is very powerful when combined with the opportunity to leverage the professional skills students are in the process of developing. JI is engaging students in this way to create an alumni army of philanthropists who will enter the workforce with a unique perspective that will not only benefit the AEC industry but the world (Lau, 2016).

\section{Cal Poly CM Senior Project Program}

Cal Poly has a strong tradition of Learn-by-Doing. The University promotes undergraduate research through a capstone senior project experience. These types of activities have shaped, defined, and distinguished the University from its very early beginnings.

Mission Statement: Cal Poly fosters teaching, scholarship, and service in a learn-by-doing environment where students and faculty are partners in discovery. As a polytechnic university, Cal Poly promotes the application of theory to practice. As a comprehensive institution, Cal Poly provides a balanced education in the arts, sciences, and technology, while encouraging crossdisciplinary and co-curricular experiences. As an academic community, Cal Poly values free inquiry, cultural and intellectual diversity, mutual respect, civic engagement, and social and environmental responsibility.

\section{Approved by President Baker January 16, 2007}

The Construction Management Department at Cal Poly also has a strong tradition of conducting student led undergraduate senior projects that align with this mission statement. Nine years ago, the CM Department renewed its commitment to learn-by-doing by revamping its senior project experience to encourage students to pursue both undergraduate level research-based and projectbased projects. Since Winter Quarter 2010, construction management students have executed over 500 senior projects. However, less than 100 projects have been project-based rather than research based. The reason for fewer project-based projects is primarily due to the difficulty in finding nonprofit projects which meet the program's criteria and funding to construction them.

\section{Cal Poly CM - JI Collaboration}

There is a strong and very obvious congruency with Cal Poly's and JI's mission statements that naturally align, making the CM-JI partnership work so successfully. The collaboration between the Cal Poly Construction Management Department and Journeyman International is personified in a single person - Daniel Wiens. Daniel was a construction management student in the Cal Poly CM program. He has continued the strong tradition of undergraduate senior projects that embody the Learn-by-Doing philosophy of the University. Daniel's own project-based senior project designed and constructed a dental clinic in Independence, Belize through Global Outreach Mission (Lau, 
2016). From Daniel's senior project experience, JI was born to give future students the same opportunity. Such projects allow students to combine their undergraduate senior project requirements with their desire to help others in a way that furthers their education and skills in the AEC field.

This JI-CM collaborative program first engages an architecture student with a project and as the project develops a structural engineer is brought on board as part of the team and later a construction management student. These have traditionally been Cal Poly students, but the program has grown and expanded to other universities and non-profit organizations. The JI timeline for this interdisciplinary process is designed to align precisely with the academic calendar. The existing structure for senior projects for the disciplines involved makes the program adoption easy for professors. For the architecture students, the deliverables include extensive research, schematic design, final design, architectural drawings, and a cohesive report that incorporates work by all three disciplines. The architectural engineering students support the architecture students with material selections and structural grid, as well as creating engineering drawings and calculations. The construction management students act as 'project managers', taking a leadership role in collaboration throughout the interdisciplinary process, in addition to several other deliverables outlined below. Clients understand that the services were provided free by university students practicing in these fields. Once the students have completed their scope of work, JI coordinates with professionals in the project country to review, modify, and adopt all design liability. When appropriate, JI takes the students to the project site prior to any design work. While these site visits are invaluable for the final product, the impact this cultural experience has on the students is profound.

The project deliverables include the design, structural engineering and pre-construction services expected of professionals with the client understanding that the services were provided free by university students practicing in these fields.

Project deliverables for the team include many of the following:

- Schematic and Design Development Drawings and Program

- Structural Plans

- Storm Water Pollution Prevention Plan (SWPPP)

- Phasing and Site Logistics Plan

- Feasibility Plan

- Scope Analysis

- Net-Zero Standards

- Conceptual Schedule

- Site Utility and Soils Analysis

- Hazard and Risk Assessment

- Constructability Review

- System Analysis Report (material integration)

- Conceptual Estimate and Material Take-Off

- Construction Site Safety Plan

The primary focus of the JI-CM partnership is on the design and pre-construction elements of the project. A site visit, while desirable, is not required in order to achieve these tasks. Students have only occasionally had the opportunity to visit the country in which the project was assigned. Costs for such trips are sometimes partially covered by the "owner", and are often supplemented by student teams either fundraising or self-funding the remaining costs. To provide the client services identified 
above little hard costs are incurred by the University or JI. The resources utilized to complete these tasks are primarily student work, with the support of faculty mentoring, and program coordination.

\section{Methodology}

To get a sense of the impact these projects have had on construction management students, evaluation forms and exit surveys were conducted with all twenty-three Cal Poly senior CM students who participated in the JI program from the Spring of 2015 to Spring of 2019. Appendix A identifies the project location, title, and the academic quarter the project was completed. Data comes from individual student surveys, project papers, and a reflection exercise executed similarly each quarter. Figure 1 (below) highlights the four high-engaging learning experiences this program has achieved and graphically demonstrates the value and rarity of students being exposed to all four at the same time. This figure also shows the vessels used to accomplish these goals. Specifically, JI provided the international non-profit projects, and Cal Poly CM provided the students who were motivated to complete this type of undergraduate senior project.

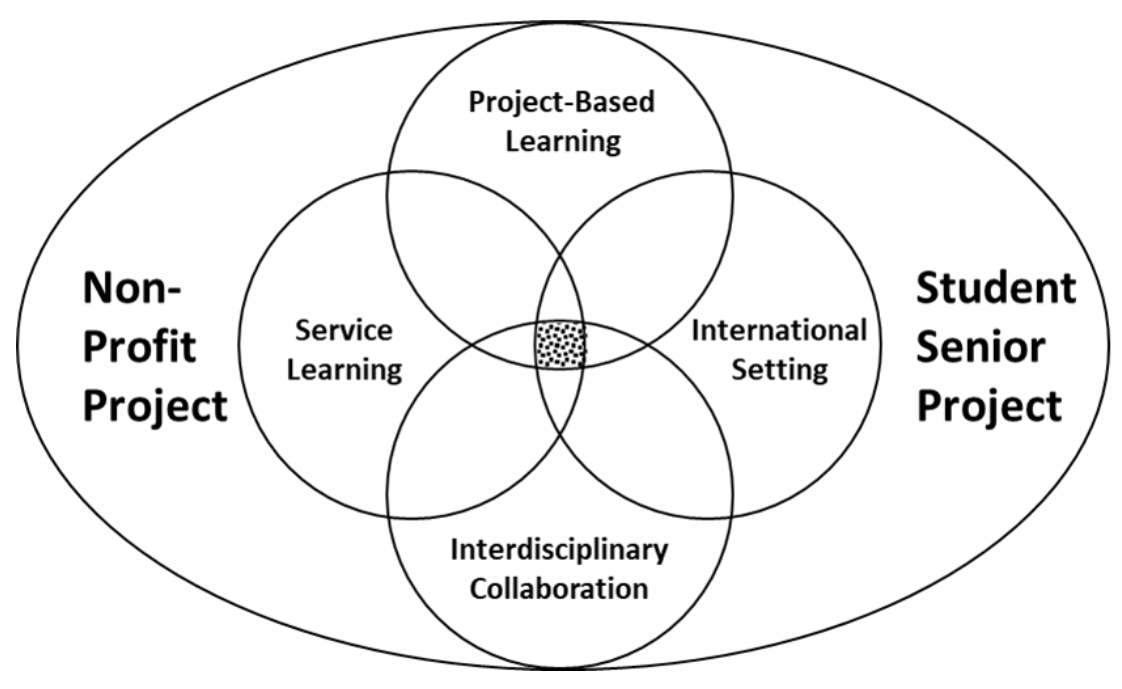

Figure 1: Intersection of high-engaging learning experiences and the vessels used.

\section{Results and Analysis}

In an attempt to relate the twenty three project points of data $(n=23)$ in a cohesive and effective way, the variety of student responses were first categorized, then listed, and finally emphasized by number of occurrences in a series of headings and descriptions.

Building Type (Occurrences):

Education or Vocational School (9), Community or Multi-Purpose Center (8), Library (2), Youth Sports or Recreation Facility (2), Medical or Treatment Facility (1), and Housing (1).

Building Location (Occurrences):

Rwanda (9), Brazil (2), Dominican Republic (2), Philippines (1), Nicaragua (1), India (1),

Tanzania (1), Burkina Faso (1), Uganda (1), Malawi (1), Cameroon (1), Zimbabwe (1), and Haiti (1). 
Satisfaction Rating (Occurrences): Specific survey question asked - "How satisfied are you with the "Senior Project Experience" you received (1-10) - "1" = least and "10" = most satisfied?

The satisfaction rating were as follows: "10" (6)," 9" (7), "8" (4), "7" (5), "6" (1). Reasons for the "higher scores" are discussed in other areas of this paper. Reasons for the "lower scores" included design work not being completed in a timely manner to complete the CM student's work. Other reasons for lower scores included vague project assumptions, student dissatisfaction with the quality of their own work, inability to visit the site, disappointment that constructing the project was not possible, and frustration with the amount of time required to work on the project.

Primary Challenges \& Lessons Learned (Occurrences): Communication and coordination (8) that is open, clear, direct, timely, and concise. Standards versus norms (3) construction standards and local building norms in a foreign country. Out of comfort zone (2) large project, interdisciplinary, pre-con services, and third-world country. Collaboration (2) particularly between interdisciplinary team members and with the client.

Patience with process (2) too much pressure on the design process had negative impacts.

Proactive and persistence (1) was necessary to get things done and stay on schedule.

Developing strong relationships (1) with all parties involved in the project.

Aligning the work (1) all elements of the preconstruction package must be aligned with each other. Lack of information (1) schedule, estimate, and construction data was conceptual and unverified. Staying flexible (1) as it related to expectations, deliverables, different ideas, and solutions. Problem solving (1) dealing with unknowns and working without an "academic net".

Communication and/or some element of that idea was the most common lesson learned or challenge identified by the CM students. The element of communication also permeates many of the other items on the list including collaboration, patience, persistence, and relationships. As related by the students in the survey, these other items also attributed to and increased the difficulty of their communication challenge. Students often lack experience with these kinds of communication challenges in the class room. Students are rarely required to communicate with other majors in an interdisciplinary environment, where pre-construction services are dependent on information provided by other parties in a timely manner. Further complicating these internal communication challenges was dealing with a client that resides in a third-world country.

\section{Discussion and Conclusions}

Through the student's senior project or thesis work, JI gave them access to "real-world" humanitarian projects. This is a far cry from the projects students normally work on which either have no chance of getting built or are based on some made-up theoretical academic exercise. Working on actual projects gave the students a real sense of meaning and purpose that was both impactful and rewarding. Students also benefited from the humanitarian aspects of these projects which commonly occur in countries other than the United States. In addition to the lessons learned above, working on a project in a foreign country takes the American student outside their comfort zone. Working on international projects is an eye-opening and challenging experience for students with no common and/or restrictive building codes, having to conform to unusual building systems, and utilizing materials native to that country.

The benefits for construction management students who chose (and were selected) for the program were clearly substantial, robust, and will last them a lifetime. Placed in unfamiliar situations students were out of their "comfort zone" where the greatest acquisition tends to occur. The lessons students acquired through this experience will serve them in both the construction industry and in life. The 
best way to summarize this experience for construction management students are the quotes collected in Appendix B from the "lessons learned" or "reflections" portions of the senior project write-ups. This author's favorite student quote, which is indicative of many student's experiences, states "All in all, this project taught me more than I could have anticipated and it furthered my ability to leave Cal Poly with confidence in my skill set and a desire to continue to learn more about the many different facets of construction."

This case study is limited in scope, as it only looks at the JI-CP program from a Cal Poly CM student perspective. Future research could be done to better understand the perspective of the Architectural and Architectural Engineering students involved in the program. The perspective of other members of the design build team may prove enlightening and augment the insight gained from the CM students. If you are interested in reading more details about these construction management students' senior project experiences, many of their full submissions can be found using the following link: https://digitalcommons.calpoly.edu/cmsp/ and in the search terms type "Journeyman International".

\section{References}

Barlow, P. (2009). Case study in implementing a service-learning class in a construction management curriculum. Associated Schools of Construction International Proceedings of the $45^{\text {th }}$ Annual Conference. University of Florida, Gainesville, Florida, April 1-4, 2009.

Bernstein, B. (2006). Using a service-learning project to enhance collaborative learning in a construction curriculum. Associated Schools of Construction International Proceedings of the $42^{\text {nd }}$ Annual Conference. Colorado State University, Fort Collins, Colorado, April 20-22, 2016.

Cal Poly Construction Management Department Website. (2019, October 15). Senior Projects, [WWW Document]. URL https://construction.calpoly.edu/content/current/senior-projects.

Cline, C., Robson, K., and Kroth, M. (2014). Construction management service learning: a "how to" process for success. International Journal of Service Learning in Engineering: University Park Vol. 9, Iss. 2, (Fall 2014): 85.

Farrow, B., Kramer, S., and Meek, D. (2011). International short-term service learning trip: assessing student perceptions. Associated Schools of Construction International Proceedings of the $47^{\text {th }}$ Annual Conference. University of Nebraska-Lincoln, Omaha, NE, April 6-9, 2011.

Hardin, M., Eribes, R., and Poster, C. (2006). From the studio to the streets: service-learning in planning and architecture. Sterling, VA: Stylus

Holley, P., Emig, J., \& Albright, E. (2012). Collaborative professional services: a case study in graduate outreach. Associated Schools of Construction International Proceedings of the $48^{\text {th }}$ Annual Conference. Birmingham City University, Birmingham, UK, April 11-14, 2012.

Hwang, S. \& McCrary, S. (2010). Incorporating project-based service-learning into a course: challenges, lessons, and recommendations. Associated Schools of Construction International Proceedings of the $46^{\text {th }}$ Annual Conference. Wentworth Institute of Technology, Boston, Massachusetts, April 23-25, 2010. 
Journeyman International. (2019, October 15). Journeyman International Annual Report - 2017. [WWW Document]. URL https://drive.google.com/file/d/1bEWQp8qNAArilmJXhYLsz05dW2zBuzm/view.

Lau, W., (November 4, 2016). Q+A: Daniel Wiens, Journeyman International. Architect Magazine, [WWW Document] URL https://www.architectmagazine.com/practice/q-a-daniel-wiens-journeymaninternational.

Lu, H., Connell, E., Wang, G. (2009). Evaluate the impact of a summer study abroad program to the students in construction management. Associated Schools of Construction International Proceedings of the 45 th Annual Conference. University of Florida, Gainesville, FL, April 1-4, 2009.

Maldonado, G. \& Moore, B. (2010). Integrating design in construction service-learning. Associated Schools of Construction International Proceedings of the $46^{\text {th }}$ Annual Conference. Wentworth Institute of Technology, Boston, Massachusetts, April 23-25, 2010.

Olbina, S., Mehany, M. \& Jesse, K. (2018). Service learning project (SLP) implementation and assessment in the construction management programs. Associated Schools of Construction International Proceedings of the $54^{\text {th }}$ Annual Conference. Constructium, Minneapolis, Minnesota, April 20-22, 2018.

Ruwanpura, J. and Brown, T. (2006). Innovative final-year undergraduate design project course using an international project. Journal of Professional Issues in Engineering Education \& Practice, ASCE, October 2006, 297-305.

Soibelman, L., Sacks, R., Akinici, B., Dikmen, I., Birgonul, R., and Eybposh, M. (2011). Preparing civil engineers for international collaboration in construction management. Journal of Professional Issues in Engineering Education \& Practice, ASCE, July 2011, 141-150.

\section{APPENDIX A - Student Project List}

\begin{tabular}{|c|c|c|c|}
\hline Student & Project Location & Project Title & Quarter - Year \\
\hline (1) & Tacloban, Philippines & Community Center & Spring 2015 \\
\hline (2) & Jinotega, Nicaragua & Young Life Summer Camp & Spring 2015 \\
\hline (3) & Andhra, India & Leadership Vocational Center & Spring 2016 \\
\hline (4) & Nova Friburgo, Brazil & Eco Caminhos Vocational Center & Spring 2016 \\
\hline (5) & Rugu Village, Tanzania & Boarding School for Deaf & Spring 2016 \\
\hline (6) & Bobo Dioulasso, Burkina & Maranatha Hospital & Spring 2016 \\
\hline (7) & Kabale, Uganda & Kihefo Vocational Center & Spring 2016 \\
\hline (8) & Bihongora, Rwanda & Women's Aquaculture Cooperative Program & Spring 2017 \\
\hline (9) & Various Locations, Rwanda & Hut 2 Hut - Tourist Housing Project & Spring 2017 \\
\hline (10) & Pernambuco, Brazil & Nossa Escola de Terra Elementary School & Spring 2017 \\
\hline (11) & El Cibao, Dom. Republic & Library and Community Center & Spring 2018 \\
\hline (12) & Villa Tapia, Dom. Rep. & Vocational Village and Medical Clinic & Spring 2018 \\
\hline (13) & Lilongwe, Malawi & The Malawi City Cottage & Spring 2018 \\
\hline (14) & Musanze, Rwanda & Community Center and Coffee Cooperative & Spring 2018 \\
\hline (15) & Mamfe, Cameroon & Youth DREAM Soccer Academy & Spring 2018 \\
\hline (16) & Bulawayo, Zimbabwe & Rural School Development Program & Spring 2018 \\
\hline$(17)$ & Mahoko Village, Rwanda & Karambo River Master Plan & Spring 2018 \\
\hline$(18)$ & Agahoozo-Shalom, Rwanda & Women's COOP and Community Center & Spring 2018 \\
\hline$(19)$ & Sunzu Yacu, Rwanda & The Kalisher Multi-Purpose Center & Spring 2018 \\
\hline (20) & Kigali, Rwanda & Kilimbi Community Center and Eco-Lodge & Spring 2019 \\
\hline
\end{tabular}




\author{
Bihongora, Rwanda \\ Les Cayes, Haiti \\ Kaseke Village, Rwanda
}

Bihongora Library

Mornes Briux Primary School

Rubagabaga Community Center
Spring 2019

Spring 2019

Spring 2019

\section{APPENDIX B - Germaine Student Quotes}

(1) "...taking a proactive approach is absolutely necessary if you want things to be completed on schedule".

(2) "The built environment literally affects the standard of living of whole countries and projects that focus on bringing those less fortunate into better position in life will now have a larger focus in my future".

(3) "Working with an architect, structural engineer, and owner is guaranteed in the future, and learning how to work with a project team during college was a good taste of what to expect in the industry".

(4) "My college education in Construction Management has taught me about traditional construction primarily within the U.S. It did not really prepare me for the regulations (or lack of), cost of materials, and non-traditional construction methods that may be used in other countries".

(5) "Though there were tough aspects of the project, there were a lot of learning moments and I feel like I'm ready to take on another big project".

(6) "Foreign construction is very different than domestic projects, especially when they are procured for a nonprofit organization...".

(7) "I view my education as an opportunity to do good in the world and I am happy I got a chance to do this."

(8) "This process showed me a different side of the design-process... I was able to see more clearly the relationship between the owner, architect, and engineer, and realize the problems the each entity faced...".

(9) "I learned the importance of establishing communication early on in developing the project... and keeping each other informed about updates to the design....".

(10) "The first of many obstacles was communication. It was important to create a history of decision tablet... which was incredibly valuable because there was limited communication..."

(11) "I understand the complexity that it takes in order for these projects to be built and I have a deeper compassion for those that need these facilities all over the world."

(12) "This project was definitely a step out of my comfort zone... and helped my independence in doing project deliverables of pre-construction".

(13) "When working in an interdisciplinary group on campus it can be easy to lose track of each other....therefore it is important to set baseline communication standards."

(14) "Overall, this project gave me a better appreciation for the work that architects and engineers do to make the work of the construction manager possible."

(15) "Empathy for the goals of the person you are communicating with and a focus on pushing for the information you need is something that can be carried on into industry."

(16) "Toward the end of the project we focused on having more weekly phone calls, rather than just emailing, which helped solve many of the miscommunication issues."

(17) "I know my interdisciplinary experience will be able to carry over ... and really tested me about what I know and what I struggle with. This experience has enlightened by both as a person and a construction manager."

(18) "The project forced me to go deeper than a superficial level that I am use to in school, to really research a problem and look for an answer that might not be there."

(19) "Building practices and material costs in Rwanda are completely different than in the US....it was difficult correlating the construction means and safety practices I have learned....to those of a third world country." (20) "I have gained even more respect for my peers in Architecture and Engineering Departments after seeing them transform a raw piece of land into the project design we now have.

(21) "These skills (developed through this program) will allow me to be more adaptable, more of a critical thinker, and to never want to stop learning about the built environment".

(22) "One of the hardest parts about completing my deliverables were the amount of unknowns. I think because of this I learned how to be creative while staying realistic".

(23) "Interdisciplinary work relies on team member trust to adequately communicate intention.... (through) a cloud-based system... without it, design projects take more time and become less synthesized". 